\title{
IMPLEMENTATION OF INTERPROFESSIONAL COLLABORATION PRACTICES IN TYPE B TEACHING GENERAL HOSPITALS: A MIXED METHODS STUDY
}

\author{
Nurul Aida Fathya ${ }^{1,2^{*}}$, Christantie Effendy ${ }^{3}$, Yayi Suryo Prabandari ${ }^{4,5}$ \\ ${ }^{1}$ Mahasiswa Program Studi Magister Bioetika Sekolah Pascasarjana Universitas Gadjah Mada, \\ ${ }^{2}$ Fakultas Kedokteran Universitas Jenderal Achmad Yani, Cimahi - INDONESIA \\ ${ }^{3}$ Departemen Keperawatan Medikal Bedah, Fakultas Kedokteran, Kesehatan Masyarakat dan Keperawatan Universitas Gadjah \\ Mada, Yogyakarta - Indonesia \\ ${ }^{4}$ Program Studi Magister Bioetika Sekolah Pascasarjana Universitas Gadjah Mada, Yogyakarta - INDONESIA \\ ${ }^{5}$ Departemen Ilmu Perilaku Kesehatan, Lingkungan dan Kedokteran Sosial, Fakultas Kedokteran, Kesehatan Masyarakat dan \\ Keperawatan, Universitas Gadjah Mada Yogyakarta - INDONESIA
}

Submitted: 23 Sep 2020; Final Revision from Authors: 14 Apr 2021; Accepted: 23 Apr 2021

\begin{abstract}
Background: The concept of patient centered health services encourages interprofessional collaborative practice (IPCP), including teaching hospitals. IPCP in teaching hospitals are expected to be implemented properly as a role model for students. Students in academic stage are expected to understand the concept of interprofessional education (IPE) and apply IPCP concept during clinical practice. This study aimed to determine the implementation of IPCP and various factors related to IPCP in teaching hospitals.

Methods: This study used a mixed methods-sequential explanatory design with the subjects of healthcare professionals at RSUD R Syamsudin SH recruited using systematic random sampling. The research began with collecting quantitative data to measure the implementation of IPCP using the Indonesian version of the Assessment of Interprofessional Team Collaboration Scale-II (AITCS-II), continued with collecting qualitative data with in-depth interviews to explored IPCP and various factors associated with its implementation.

Results: A total of 320 respondents filled out the AITCS-II questionnaire and 11 participants were interviewed deeply. More than $66 \%$ of respondents had good collaboration in each domain; 73,8\% of respondents had good collaboration in IPCP; profession background significantly contributed IPCP $(p<0.05)$. Qualitative analysis was carried out with a semantic theme and obtained 3 themes: non-ideal IPCP implementation, perception of IPCP domains by healthcare professionals and barriers in implementing IPCP.

Conclusion: The perception of IPCP that well implemented may resulted from improper understanding of IPCP. We still found barrier in implementing IPCP related to stereotypes, hierarchical culture, interprofessional communication and regulation.
\end{abstract}

Keywords: AITCS II, interprofessional collaboration practice, teaching hospital.

\section{ABSTRAK}

Latar belakang: Konsep pelayanan kesehatan yang berfokus pada pasien mendorong praktik kolaborasi interprofesional (PKIP), tidak terkecuali rumah sakit pendidikan. Rumah sakit pendidikan diharapkan dapat menerapkan PKIP dengan baik sebagai role model bagi peserta didik. Peserta didik diharapkan memahami

$\overline{\text { *corresponding author, contact: nurul.aida@lecture.unjani.ac.id }}$ 
konsep interprofessional education (IPE) pada tahap akademik dan menerapkan konsep PKIP pada saat praktik klinis. Penelitian ini bertujuan mengetahui penerapan PKIP dan berbagai faktor yang terkait dengan penerapan PKIP di RS tipe B pendidikan.

Metode: Penelitian ini menggunakan mixed methods-sequential explanatory design dengan tehnik pengambilan subjek secara acak sistematis pada tenaga kesehatan di RSUD R Syamsudin SH. Penelitian diawali dengan pengumpulan data kuantitatif untuk mengukur penerapan PKIP menggunakan the Assessment of Interprofessional Team Collaboration Scale-II (AITCS-II) versi bahasa Indonesia dan dilanjutkan dengan pengumpulan data kualitatif berupa wawancara mendalam untuk mengeksplorasi berbagai faktor yang terkait dengan penerapan PKIP.

Hasil: Sejumlah 320 tenaga kesehatan mengisi kuesioner AITCS-II dan 11 partisipan berlanjut untuk dilakukan wawancara mendalam. Lebih dari 66\% responden menerapkan kolaborasi baik pada tiap domain; $73,8 \%$ responden menerapkan PKIP secara baik; jenis profesi memengaruhi PKIP $(p<0,05)$ secara bermakna. Analisis data kualitatif secara tema semantik mendapatkan 3 tema yakni pelaksanaan PKIP dirasakan belum ideal, pemahaman komponen kolaborasi oleh para tenaga kesehatan dan kendala pelaksanaan PKIP.

Kesimpulan: Persepsi telah dilakukannya penerapan PKIP yang baik dapat terjadi karena pemahaman KIP yang kurang tepat, karena pada pelaksanaannnya PKIP masih menghadapi kendala terkait stereotip, budaya hierarki, komunikasi interprofesional dan regulasi.

Kata kunci: AITCS II, praktik kolaborasi interprofesional, rumah sakit pendidikan.

\section{PRACTICE POINTS}

- Penerapan IPE dalam konteks praktik klinis di RS Pendidikan membutuhkan pemahaman yang sama antara institusi pendidikan dengan RS sebagai wahana, komitmen serta dukungan sistem agar dapat terlaksana dengan ideal.

- AITCS II versi bahasa Indonesia memiliki nilai validitas dan reliabilitas baik, yang dapat digunakan untuk mengevaluasi pelaksanaan PKIP di RS pendidikan.

\section{PENDAHULUAN}

Rumah sakit merupakan tempat berkumpulnya berbagai macam tenaga kesehatan yang menjalankan profesinya dalam pelayanan kesehatan. Profesi kesehatan bukan hanya terfokus pada dokter, tapi juga profesional dari berbagai disiplin ilmu yang berupaya menyediakan pelayanan berkualitas bagi pasien. ${ }^{1}$ Pergeseran konsep pelayanan kesehatan dari profession center menjadi patient center mendorong pelaksanaan praktik kolaborasi interprofesional (PKIP). ${ }^{2,3}$ Konsekuensi dari konsep patient center adalah tersedianya tenaga kesehatan yang mampu menjalankan perannya secara maksimal, baik dalam satu profesi (intraprofesional) maupun antar profesi kesehatan (interprofesional)., Upaya untuk mengubah profesionalisme individu menjadi profesionalisme tim membutuhkan komunikasi, kemitraan, pengambilan keputusan bersama, koordinasi dan kerja sama.,2,4-6 Tujuannya agar dapat meningkatkan kepuasan pasien, keselamatan pasien, meningkatkan kesehatan masyarakat, dan mengurangi biaya perawatan. ${ }^{2.4}$

Sejak diperkenalkannya kolaborasi interprofesional oleh World Health Organization (WHO), institusi pendidikan dan pelayanan kesehatan mulai mengembangkan serta menerapkan konsep kolaborasi interprofesional. ${ }^{4}$ Pada institusi pendidikan kesehatan dikenal sebagai interprofessional education (IPE) sedangkan pada institusi pelayanan kesehatan dikenal sebagai PKIP., ${ }^{4}$ Konsep ini terpisah 
namun tetap terkait, karena institusi pelayanan kesehatan menjadi sarana penerapan IPE bagi peserta didik tingkat profesi. Tahapan pendidikan profesi dilaksanakan dalam bentuk pembelajaran klinik dan pembelajaran komunitas yang menggunakan berbagai tingkat pelayanan kesehatan nyata yang memenuhi persyaratan sebagai tempat praktik. ${ }^{7}$

Rumah sakit pendidikan digunakan institusi pendidikan sebagai sarana untuk mencapai kompetensi peserta didiknya. Rumah sakit ini memiliki fungsi pelayanan juga pendidikan, selain mengembangkan kompetensi interprofesional juga membentuk karakter profesional bagi peserta didik. Saat menjalankan fungsi pendidikan tersebut diharapkan PKIP dapat diterapkan dengan baik sebagai role model bagi peserta didik. ${ }^{8}$ Idealnya lokasi pendidikan ini menerapkan PKIP, karena IPE dilaksanakan mulai dari tahap akademik hingga tahap profesi, dengan tujuan menghubungkan teori yang didapatkan dan praktik yang dijalankan di RS. ${ }^{9}$

Penerapan IPE pada sarana pendidikan klinik dapat menghadapi tantangan, karena PKIP dapat berbedabeda pada tiap institusi. Hal ini dipengaruhi oleh karakteristik sosial budaya dalam suatu institusi atau konsep kolaborasi yang ditetapkan masing-masing organisasi profesi. ${ }^{2,4}$ Findyartini, dkk menemukan bahwa PKIP dapat lebih mudah diterapkan pada fasilitas kesehatan primer, karena skala perawatan kesehatan lebih kecil dibandingkan dengan rumah sakit. Komunikasi dan kebersamaan antar tenaga kesehatan menjadi faktor yang mendukung, sedangkan terbatasnya personel dan beban tugas yang tidak seimbang menjadi penghambat PKIP di fasilitas kesehatan primer. $^{10}$

Evaluasi penerapan PKIP dapat dilakukan dengan menggunakan instrumen. Saat ini terdapat berbagai jenis instrumen yang dikembangkan untuk dapat menilai penerapan PKIP oleh tenaga kesehatan. Salah satunya adalah the Assessment of Interprofessional Team Collaboration Scale-II (AITCS-II) yang dikembangkan oleh Orchard, dkk. ${ }^{5}$ Penelitian ini bertujuan menilai penerapan PKIP menggunakan kuesioner AITCS. II versi bahasa Indonesia yang telah diuji dan juga menggali lebih dalam berbagai faktor yang berpotensi memengaruhi penerapan PKIP pada RS pendidikan.

\section{METODE}

\section{Konteks}

Rumah sakit umum daerah (RSUD) sebagai rumah sakit rujukan sekunder memberikan pelayanan medis, keperawatan, kebidanan, penunjang medis dan nonmedis; sehingga beragam tenaga kesehatan terlibat didalamnya. ${ }^{11}$ Rumah sakit pendidikan memiliki fungsi pelayanan juga pendidikan, sehingga diharapkan peserta didik tahap profesi dapat melihat penerapan IPE dalam konteks nyata. Rumah sakit umum daerah (RSUD) R Syamsudin SH dipilih sebagai lokasi penelitian karena merupakan RS tipe B dan RS pendidikan satelit 4 fakultas kedokteran dan beberapa institusi pendidikan kesehatan. Rumah sakit umum daerah (RSUD) R Syamsudin SH merupakan RS tipe B pendidikan yang terletak di kota Sukabumi, provinsi Jawa Barat. Rumah sakit umum daerah (RSUD) R Syamsudin SH memiliki pelayanan spesialistis dan penunjang dengan kapasitas rawat inap sebanyak 726 tempat tidur, dan 885 orang tenaga kesehatan. ${ }^{12}$

\section{Desain penelitian}

Metode penelitian ini adalah campuran, dengan sequential explanatory design dengan subjek diambil dari tenaga kesehatan di RSUD R Syamsudin SH dengan sampling acak sistematis. Penelitian kuantitatif dengan rancangan potong lintang dilakukan dahulu untuk mendapatkan gambaran pelaksanaan PKIP dengan menggunakan kuesioner AITCS-II. Selanjutnya penelitian kualitatif dengan rancangan fenomenologi dilakukan untuk menjelaskan penerapan PKIP dan mengeksplorasi faktor-faktor pendukung atau penghambat PKIP dengan wawancara mendalam. Kriteria inklusi adalah tenaga kesehatan (dokter, dokter gigi, perawat, bidan, apoteker, dietisien, dan fisioterapis) yang telah berpraktik di RSUD R Syamsudin SH minimal lima tahun.

\section{Pengambilan data}

Untuk tahap pertama, dilakukan teknik sampling acak sistematis dengan mempertimbangkan proporsi masing-masing tenaga kesehatan di rumah sakit. Ukuran sampel minimum terhitung sebanyak 303 
(dengan sensitivitas 5\%, tingkat kepercayaan 95\%, dan dropout yang diantisipasi sebesar 10\%). Jumlah sampel tiap kelompok tenaga kesehatan disesuaikan dengan jumlah tenaga kesehatan di rumah sakit yang berjumlah 885 dan proporsi tenaga kesehatan yang akan diambil. Sebanyak 360 responden diberikan tautan kuesioner dan persetujuan setelah penjelasan secara daring (adanya pembatasan sosial akibat COVID-19). Tahap kedua diambil sebanyak 11 partisipan yang sebelumnya telah mengisi kuesioner pada tahap pertama. Variasi profesi, unit kerja, usia, pendidikan serta nilai kuesioner AITCS-II diperhatikan pada partisipan yang diwawancara hingga didapatkan saturasi data. Setiap partisipan diwawancara tersendiri oleh peneliti selama 3560 menit, dan dilanjutkan transkripsi rekaman wawancara tersebut.

\section{Instrumen}

Kuesioner AITCS-II versi bahasa Indonesia yang telah divalidasi digunakan pada tahap pertama penelitian ini. AITCS-II pada awalnya dikembangkan di Kanada untuk menilai penerapan PKIP, dengan 23 pertanyaan yang terdiri atas 3 domain yakni: kemitraan ( 8 butir), kerja sama ( 8 butir) dan koordinasi (7 butir). ${ }^{8}$ Instrumen ini mengalami proses adaptasi: terjemahan oleh dua orang penerjemah dan terjemahan balik, tinjauan panel oleh 3 ahli dan diujikan kepada 50 responden. Hasil pengujian menunjukan seluruh pertanyaan valid (nilai korelasi Pearson $>0,284$ ) dan memiliki reliabilitas yang tinggi (nilai Cronbach \0,937). Daftar pertanyaan semi terstruktur digunakan sebagai panduan wawancara untuk mengeksplorasi pengalaman PKIP dan faktorfaktor yang mempengaruhi PKIP.

\section{Analisis data}

Nilai rerata dan standar deviasi dihitung pada tiap domain dan kemudian secara keseluruhan. Nilai tersebut dikelompokan sesuai kategori penerapan PKIP yakni: kolaborasi baik jika nilai 4.0 atau lebih, 3.0 hingga 3.9 menunjukkan bergerak menuju kolaborasi; 1.0 hingga 2.9 menunjukkan perlunya pengembangan praktik kolaborasi. $^{5}$ Analisis kuantitatif diselesaikan dengan menggunakan
SPSS 22.0. Analisis deskriptif dilakukan untuk mendeskripsikan karakteristik responden dan nilai PKIP. Analisis bivariat menggunakan uji Kruskal Wallis untuk variabel profesi dan status kepegawaian dan uji korelasi Spearman untuk variabel usia, pendidikan, lama praktik dan lama bekerja dengan tim.

Setelah transkrip selesai, divalidasi dengan cara melakukan member checking. Transkrip tersebut kemudian siap dianalisis oleh peneliti dan juga independent coder. Peneliti dan independent coder melakukan tahapan coding, re-coding, kategorisasi hingga penentuan tema pada tempat yang terpisah, kemudian dicari kesepakatan tema. Tahapan analisis berikutnya adalah analisis gabungan dengan cara integrasi, menghubungkan data hasil penelitian kuantitatif dengan data hasil penelitian kualitatif. ${ }^{13}$

\section{Aspek etik}

Penelitian ini telah mendapat persetujuan dari Komite Etik Penelitian Fakultas Kedokteran, Kesehatan Masyarakat dan Keperawatan Universitas Gadjah Mada dengan nomor surat KE/FK/0164/ EC/2020 tertanggal 6 Februari 2020 dan izin pada lokasi penelitian yang dikeluarkan pada bulan Maret 2020. Pengambilan data dilakukan selama periode April-Juni 2020. Setiap responden dan partisipan memberi persetujuan (informed consent) untuk ikut berpartisipasi dalam penelitian ini. Semua data kuantitatif dan kualitatif telah disimpan dengan aman dan akses hanya dapat dilakukan oleh peneliti. Nama partisipan wawancara tidak dicantumkan dalam laporan atau publikasi yang dihasilkan dari penelitian ini.

\section{HASIL DAN PEMBAHASAN}

\section{Karakteristik demografi responden}

Sejumlah 360 responden memenuhi persyaratan dan 320 (90\%) responden bersedia terlibat dalam penelitian ini. Tabel 1 menunjukan karakteristik demografi responden tahap kuantitatif. Sebagian besar responden berusia $31-40$ tahun 176 (55\%), berprofesi sebagai perawat $166 \quad(51.9 \%)$ dan berpendidikan diploma 167 (52,2\%) dan bekerja 
purna waktu 263 (82,2\%) dengan pengalaman praktik antara 5-10 tahun sebanyak 181 (56.5\%) dan mempunyai pengalaman kerja tim sebanyak 128 (40\%). Fisioterapis, dokter gigi dan dietisien merupakan profesi yang paling jarang $(<1.6 \%)$.

Tabel 1. Karakteristik demografi responden penelitian

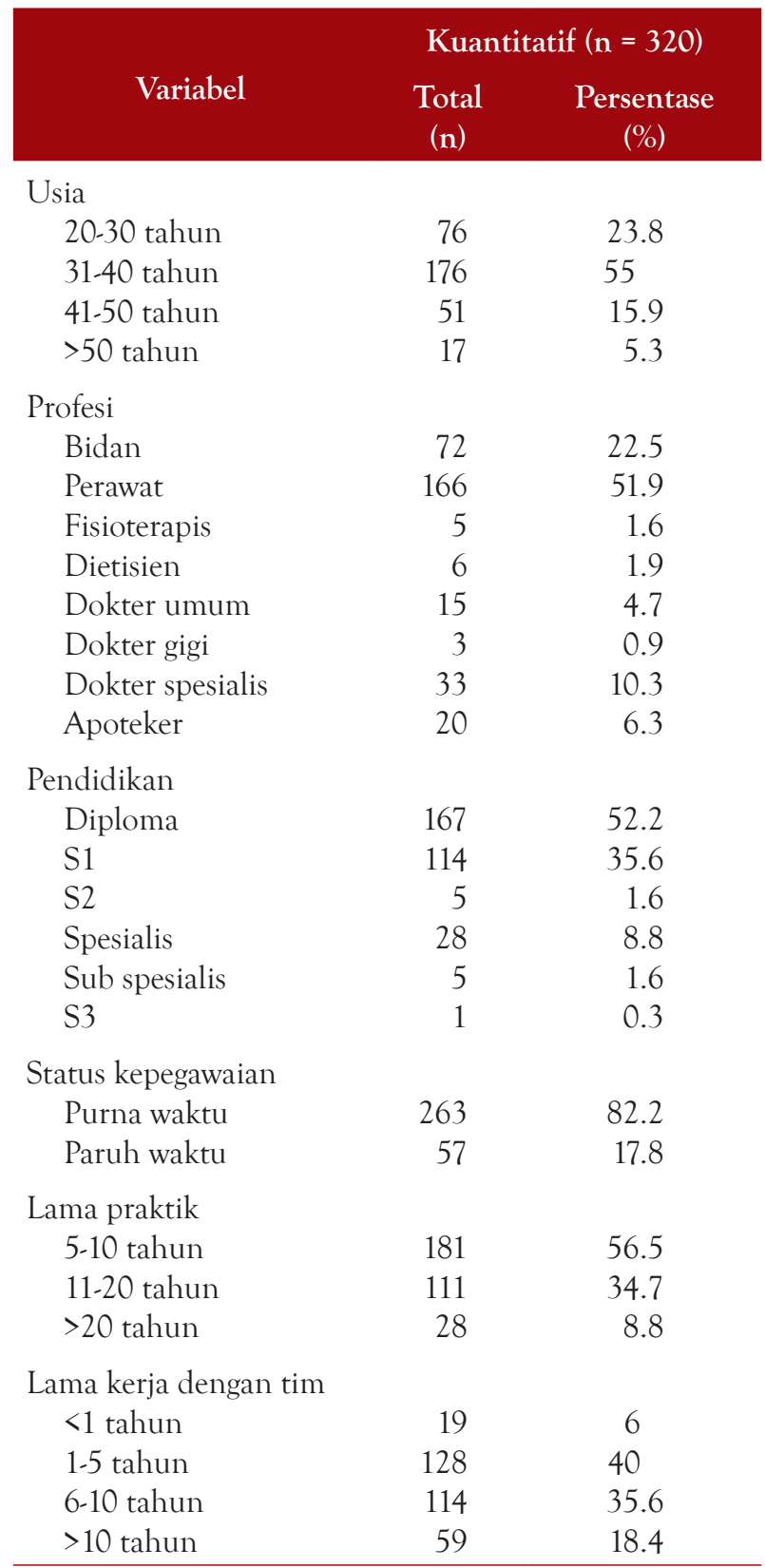

Pada tahapan kualitatif, dari seluruh partisipan terdapat 11 partisipan dengan variasi karakteristik berupa variasi profesi, unit kerja, usia, pendidikan serta nilai kuesioner AITCS II bersedia untuk dilakukan wawancara mendalam. Dua partisipan terpilih mewakili masing-masing profesi dokter spesialis, apoteker, dietisien dan perawat. Profesi bidan, fisioterapis serta dokter umum masing-masing diwakili oleh 1 partisipan.

\section{Penerapan PKIP menggunakan kuesioner AITCS-II}

Kuesioner AITCS-II menilai penerapan PKIP pada domain kerja sama, kemitraan dan koordinasi serta penerapannya secara keseluruhan. Tabel 2 menunjukan sebagian besar reponden telah menerapkan kolaborasi dengan baik. Persentase tertinggi hingga terendah dari ketiga domain yang menunjukan kolaborasi secara baik secara berturut-turut adalah domain kerja sama $(82,2 \%)$, domain kemitraan $(67,8 \%)$ dan domain koordinasi $(66,9 \%)$. Penerapan PKIP menunjukan $73,8 \%$ responden melakukan kolaborasi yang baik, 23,1\% menuju penerapan kolaborasi dan 3,1\% memerlukan kolaborasi.

Tabel 2. Penerapan kolaborasi berdasarkan domain PKIP

\begin{tabular}{llrc}
$\begin{array}{l}\text { Komponen } \\
\text { Penilaian }\end{array}$ & \multicolumn{1}{c}{$\begin{array}{c}\text { Penerapan } \\
\text { Kolaborasi }\end{array}$} & $\begin{array}{c}\text { Total } \\
\text { (n) }\end{array}$ & $\begin{array}{c}\text { Persentase } \\
(\%)\end{array}$ \\
\hline Domain & Kolaborasi baik & 217 & 67.8 \\
Kemitraan & Menuju & 92 & 28.7 \\
& kolaborasi & & \\
& Perlu kolaborasi & 11 & 3.4 \\
Domain Kerja & Kolaborasi baik & 263 & 82.2 \\
sama & Menuju & 51 & 15.9 \\
& kolaborasi & & \\
& Perlu kolaborasi & 6 & 1.9 \\
Domain & Kolaborasi baik & 214 & 66.9 \\
koordinasi & Menuju & 89 & 27.8 \\
& kolaborasi & & \\
& Perlu kolaborasi & 17 & 5.3 \\
Kolaborasi & Kolaborasi baik & 236 & 73.8 \\
interprofesional & Menuju & 74 & 23.1 \\
& kolaborasi & & \\
& Perlu kolaborasi & 10 & 3.1 \\
\hline
\end{tabular}

*Nilai keseluruhan kolaborasi interprofesional didapatkan dari penjumlahan nilai rerata 3 domain, yang kemudian dikelompokan sesuai kategori penerapan kolaborasi yakni: kolaborasi baik (nilai ${ }^{3} 4.0$ ), menuju kolaborasi (nilai 3.0-3.9) dan perlunya pengembangan praktik kolaborasi (nilai 1.0-2.9). ${ }^{8}$ 
Untuk mengetahui komponen karakteristik responden yang bermakna memengaruhi penerapan kolaborasi dilakukan analisis bivariat, tampak pada Tabel 3. Berdasarkan analisis tersebut didapatkan jenis profesi yang bermakna memengaruhi penerapan PKIP $(p=0,002)$, sedangkan untuk karakteristik responden lain tidak bermakna secara statistik ( $>>0,05)$. Tabel 3 menunjukkan bahwa sebagian besar profesi, yakni: bidan $(87,5 \%)$, perawat $(73,5 \%)$, dokter umum $(73,3 \%)$, dokter gigi $(100 \%)$, dokter spesialis $(66,7 \%)$, dan apoteker (55\%) memiliki kolaborasi yang baik. Berbeda pada profesi fisioterapis (40\%) dan dietisien (50\%) yang masuk dalam kategori menuju kolaborasi.

Tabel 3. Hubungan karakteristik responden dengan penerapan kolaborasi $(n=320)$

\begin{tabular}{|c|c|c|c|c|c|c|c|c|}
\hline \multirow{3}{*}{ Karakteristik } & \multirow{3}{*}{$\mathbf{n}^{* *}$} & \multicolumn{6}{|c|}{ Kolaborasi interprofesional } & \multirow{3}{*}{$p$ value } \\
\hline & & \multicolumn{2}{|c|}{ Kolaborasi baik } & \multicolumn{2}{|c|}{ Menuju kolaborasi } & \multicolumn{2}{|c|}{ Perlu kolaborasi } & \\
\hline & & n & $\%$ & n & $\%$ & $\mathbf{n}$ & $\%$ & \\
\hline \multicolumn{9}{|l|}{ Usia } \\
\hline 20-30 tahun & 76 & 62 & $81.6 \%$ & 11 & $14.5 \%$ & 3 & $3.9 \%$ & \multirow{4}{*}{$0,118^{\$}$} \\
\hline $31-40$ tahun & 176 & 127 & $72.2 \%$ & 45 & $25.6 \%$ & 4 & $2.3 \%$ & \\
\hline 41-50 tahun & 51 & 33 & $64.7 \%$ & 16 & $31.4 \%$ & 2 & $3.9 \%$ & \\
\hline$>50$ tahun & 17 & 14 & $82.4 \%$ & 2 & $11.8 \%$ & 1 & $5.9 \%$ & \\
\hline \multicolumn{8}{|l|}{ Profesi } & \multirow{9}{*}{$0,002^{* \#}$} \\
\hline Bidan & 72 & 63 & $87.5 \%$ & 9 & $12.5 \%$ & 0 & $0.0 \%$ & \\
\hline Perawat & 166 & 122 & $73.5 \%$ & 41 & $24.7 \%$ & 3 & $1.8 \%$ & \\
\hline Fisioterapis & 5 & 2 & $40.0 \%$ & 2 & $40.0 \%$ & 1 & $20.0 \%$ & \\
\hline Dietisien & 6 & 2 & $33.3 \%$ & 3 & $50.0 \%$ & 1 & $16.7 \%$ & \\
\hline Dokter umum & 15 & 11 & $73.3 \%$ & 4 & $26.7 \%$ & 0 & $0.0 \%$ & \\
\hline Dokter gigi & 3 & 3 & $100.0 \%$ & 0 & $0.0 \%$ & 0 & $0.0 \%$ & \\
\hline Dokter spesialis & 33 & 22 & $66.7 \%$ & 9 & $27.3 \%$ & 2 & $6.1 \%$ & \\
\hline Apoteker & 20 & 11 & $55.0 \%$ & 6 & $30.0 \%$ & 3 & $15.0 \%$ & \\
\hline \multicolumn{8}{|l|}{ Pendidikan } & \multirow{7}{*}{$0,096^{\$}$} \\
\hline Diploma & 167 & 128 & $76.6 \%$ & 39 & $23.4 \%$ & 0 & $0.0 \%$ & \\
\hline $\mathrm{S} 1$ & 114 & 82 & $71.9 \%$ & 25 & $21.9 \%$ & 7 & $6.1 \%$ & \\
\hline S2 & 5 & 3 & $60.0 \%$ & 1 & $20.0 \%$ & 1 & $20.0 \%$ & \\
\hline Spesialis & 28 & 20 & $71.4 \%$ & 6 & $21.4 \%$ & 2 & $7.1 \%$ & \\
\hline Sub spesialis & 5 & 2 & $40.0 \%$ & 3 & $60.0 \%$ & 0 & $0.0 \%$ & \\
\hline S3 & 1 & 1 & $100.0 \%$ & 0 & $0.0 \%$ & 0 & $0.0 \%$ & \\
\hline \multicolumn{8}{|l|}{ Pekerjaan } & \multirow{3}{*}{$0,435^{\#}$} \\
\hline Purna waktu & 263 & 192 & $73.0 \%$ & 61 & $23.2 \%$ & 10 & $3.8 \%$ & \\
\hline Paruh waktu & 57 & 44 & $77.2 \%$ & 13 & $22.8 \%$ & 0 & $0.0 \%$ & \\
\hline \multicolumn{8}{|l|}{ Lama praktik } & \multirow{4}{*}{$0,434^{\$}$} \\
\hline 5-10 tahun & 181 & 135 & $74.6 \%$ & 41 & $22.7 \%$ & 5 & $2.8 \%$ & \\
\hline $11-20$ tahun & 111 & 84 & $75.7 \%$ & 24 & $21.6 \%$ & 3 & $2.7 \%$ & \\
\hline$>20$ tahun & 28 & 17 & $60.7 \%$ & 9 & $32.1 \%$ & 2 & $7.1 \%$ & \\
\hline \multicolumn{8}{|l|}{ Lama kerja dengan tim } & \multirow{5}{*}{$0,188^{\$}$} \\
\hline$<1$ tahun & 19 & 17 & $89.5 \%$ & 2 & $10.5 \%$ & 0 & $0.0 \%$ & \\
\hline 1-5 tahun & 128 & 92 & $71.9 \%$ & 32 & $25.0 \%$ & 4 & $3.1 \%$ & \\
\hline 6-10 tahun & 114 & 90 & $78.9 \%$ & 22 & $19.3 \%$ & 2 & $1.8 \%$ & \\
\hline$>10$ tahun & 59 & 37 & $62.7 \%$ & 18 & $30.5 \%$ & 4 & $6.8 \%$ & \\
\hline
\end{tabular}

*) bermakna $<<0,05, \$)$ Korelasi Spearman, \#) Kruskal Wallis, **) jumlah bervariasi 
Jenis profesi menjadi satu-satunya latar belakang yang memiliki hubungan signifikan dengan penerapan kolaborasi di penelitian ini. Serupa dengan penelitian Yusra, dkk di RSUPN Ciptomangunkusumo, tidak ada perbedaan yang signifikan antara persepsi KIP dengan latar belakang usia dan lama berpraktik. ${ }^{14}$ Latar belakang profesi menjadi faktor yang signifikan dalam praktik KIP karena pada awalnya konsep yang dibuat adalah profession center, sehingga tenaga kesehatan terbiasa bekerja mandiri. Dokter masih dianggap lebih mandiri serta superior dari tenaga kesehatan lain sehingga hubungan antar profesi menjadi tidak setara dan menciptakan stereotip. ${ }^{15,16}$ Pada penelitian ini tampak pada kecilnya persentase profesi apoteker, dietisien dan fisioterapis yang menerapkan kolaborasi baik. Sejalan dengan penelitian Sari di salah satu rumah sakit di Jakarta yang menemukan profesi apoteker dan dietisien memiliki stereotip negatif yang tinggi hingga memunculkan praktik kolaborasi yang buruk. ${ }^{16}$

Meskipun usia pada penelitian ini tidak signifikan memengaruhi PKIP secara keseluruhan, tapi signifikan memengaruhi domain kemitraan. Usia berkaitan dengan kemitraan dengan pasien, tanggung jawab atas pekerjaan serta otonomi profesi dalam PKIP. Usia yang lebih muda dengan lama praktik yang lebih singkat mempersepsikan lebih banyak hambatan daripada orang yang lebih tua dengan rentang praktik lebih lama. ${ }^{10,14,17}$ Penelitian Martiningsih di RSUD Ngudi Waluyo, Blitar, menemukan bahwa lama kerja mempunyai pengaruh negatif, yakni berarti makin lama bekerja sikap tentang praktik kolaborasi makin menurun. ${ }^{17}$ Makin lama bekerjasama dalam tim, membentuk pengertian karakter personal antar anggota tim sehingga cenderung melakukan penghindaran daripada berunding saat mengatasi konflik yang terjadi. ${ }^{18}$

\section{Pelaksanaan PKIP dirasakan belum ideal}

Hasil wawancara pada tahapan kualitatif dianalisis secara tematik dan didapatkan 3 tema yakni pelaksanaan PKIP dirasakan belum ideal, pemahaman komponen kolaborasi oleh para tenaga kesehatan dan kendala pelaksanaan PKIP. Penerapan praktik KIP pada penelitian ini sebelumnya telah diukur dengan menggunakan kuesioner AITCSII pada tahapan kuantitatif, maka pada tahapan kualitatif pengalaman PKIP dieksplorasi lebih mendalam. Beberapa partisipan mengatakan bahwa praktik KIP belum dilakukan oleh semua tenaga kesehatan di RS.

"Kalau menurut saya ada sebagian yang sudah berjalan, ada juga yang belum..." (P9, perempuan, 30 tahun, diploma, bidan)

Sebagian sektor di RS telah melaksanakan kolaborasi, sektor yang dikatakan telah melakukan KIP antara lain unit geriatrik, di paviliun eksekutif dan di instalasi gawat darurat, seperti yang disampaikan responden berikut:

"...kalau kegawat daruratan itu ngga mungkin kerja sendiri ya biasanya tim kan." (P11, perempuan, 34 tahun, S1, dokter umum)

Pernyataan partisipan melengkapi hasil AITCS II yang mendapati $73,3 \%$ dokter umum yang sebagian besar bekerja di instalasi gawat darurat telah melakukan kolaborasi baik. Di Indonesia belum semua pelayanan kesehatan menerapkan PKIP, beberapa pelayanan masih menerapkan konsep kolaborasi multiprofesi seperti pelayanan intensif. ${ }^{19}$ RSUD R Syamsudin SH sendiri belum memiliki regulasi perihal PKIP, sehingga pelaksanaan PKIP tidak memiliki dasar yang kuat untuk dilaksanakan pada sektor-sektor lain. Pengalaman PKIP partisipan juga terbatas, terdapat pengalaman yang dirasakan tiga partisipan bahwa dalam praktik sebenarnya tiap profesi masih bekerja sendiri-sendiri, belum bekerjasama. Kedua dietisien dan seorang apoteker mengemukakan hal tersebut, salah satunya pada pernyataan:

\footnotetext{
"Kalau saya lihat sekarang ini kita singkatnya itu masih bekerja bersama bukan bekerja sama. Jadi masih masing-masing." (P4, perempuan, 48 tahun, S1, dietisien)
}

Hal ini menjelaskan bahwa masih adanya responden yang perlu kolaborasi pada hasil AITCS 
II pada profesi dietisien, apoteker dan fisioterapis. Berdasarkan penyataan partisipan, bekerja bersama memiliki pengertian yang sama dengan kolaborasi multiprofesional. Pernyataan tersebut berbeda dengan apa yang diungkapkan partisipan dokter :spesialis berikut

"Sebetulnya kalau yang tadi dengan farmasi itu termasuk dalam tim..." dan "Gizi termasuk juga dalam tim...” (P1, laki-laki, 48 tahun, dokter spesialis)

"Yang saya rasakan di SMF saya sih jalan. Ke semua tenaga kesehatan jalan." (P3, laki-laki, 49 tahun, dokter spesialis)

Kedua partisipan tersebut mendukung temuan AITCS II yakni 66,7\% responden dokter spesialis telah melakukan PKIP dengan baik dan merasa bahwa telah terjalin kerjasama yang ideal antar profesi apoteker dan dietisien dengan dokter spesialis. Tampak bahwa pelaksanaan yang belum ideal dapat timbul dari adanya perbedaan persepsi para tenaga kesehatan yang terlibat, seperti yang didapatkan pada tahap kualitatif penelitian ini. Sejalan dengan penelitian Fatalina, dkk yang menemukan bahwa persepsi tentang PKIP para tenaga kesehatan belum seragam karena terbatasnya informasi mengenai KIP. ${ }^{20}$ Informasi bisa didapatkan dari kegiatan formal seperti proses pendidikan, pelatihan ataupun seminar. Informasi KIP secara informal didapatkan dari interaksi dengan tenaga kesehatan lain, jurnal ataupun media elektronik. ${ }^{15,20}$

\section{Komponen kolaborasi yang dipahami para tenaga kesehatan}

Partisipan mengungkapkan pemahaman mereka tentang praktik kolaborasi sebagai interaksi multidisiplin, antar profesi, pembagian tugas hingga kesamaan tujuan. Pemahaman tersebut tampak pada pernyataan partisipan berikut:

"Kalau menurut saya kolaborasi itu adalah satu pasien ditangani dengan beberapa keilmuan." (P3, laki-laki, 49 tahun, dokter spesialis) “..kolaborasi ya kayaknya seperti itu ya kita juga semua kan nunggu advice dokter nih, terus pasti kan dokter ke perawat ya misalnya suruh ngambil lab PCV, HB, Leukosit kayak gitu kan diambil sama kita. Sama kita dikirim ke lab. Terus yang menjalankannya mah analisis lab..." (P7, perempuan, 32 tahun, diploma, perawat)

Meskipun terdapat pemahaman yang kurang tepat, enam partisipan dapat mengungkapkan pemahaman yang baik perihal PKIP. Para partisipan tersebut antara lain 2 dietisien, 2 apoteker, 1 dokter umum dan 1 fisioterapis. Pernyataan partisipan yang mengandung pemahaman yang baik diwakili oleh partisipan berikut ini:

“..berkolaborasi itu lebih ke arah kita kerja bareng kemudian kita di kerja bareng itu kita apa punya satu tujuan yang sama yang kita harus kita kayak cari jalan gimana caranya supaya kita sampai ke tujuan itu bareng-bareng gitu." (P5, perempuan, 37 tahun, S1, apoteker)

Fatalina, dkk mengungkapkan bahwa sebagian besar tenaga kesehatan belum mampu mendefinisikan KIP secara tepat, karena masih disamakan dengan konsep kolaborasi multiprofesi. ${ }^{20}$ Pemahaman KIP dianalisis lebih dalam sehingga terungkap beberapa komponen kolaborasi yang para partisipan pahami dan lakukan dalam praktik kesehariannya. Komponen kolaborasi yang ditemukan dalam tahap penelitian ini antara lain prinsip kemitraan, aspek kerjasama, dan koordinasi dan komunikasi interprofesional.

\section{a. Komponen kemitraan}

Kemitraan merupakan hal yang mendasar dalam hubungan kolaborasi. Sebagian besar partisipan mengatakan bahwa hubungan antar tenaga kesehatan adalah hubungan mitra kerja, bukan hubungan atasan dan bawahan. Memahami bahwa tenaga kesehatan lain memiliki profesionalitas dan peran dalam tim, sehingga tidak ada profesi yang dianggap lebih unggul. Namun salah satu partisipan dokter spesialis juga menyatakan bahwa hubungan antar tenaga kesehatan bisa menjadi mitra ataupun sebagai atasan. Tampak pada pernyataannya berikut: 
"..paramedis jadi mereka menjalankan instruksi dari saya." (P1, laki-laki, 48 tahun, dokter spesialis)

Cara pandang kemitraan ini didukung oleh partisipan bidan dan salah satu partisipan perawat. Mereka memahami hubungan kemitraan sebagai rekan kerja yang membantu pelaksanaan rencana terapi dokter untuk pasien, seperti pada pernyataan berikut:

"..nanti ada perintah misalnya dari dokter tersebut akan diberikan terapi apa..." (P9, perempuan, 30 tahun, diploma, bidan)

Perbedaan cara pandang hubungan kemitraan ini menimbulkan adanya anggapan dari profesi dietisien, apoteker dan fisioterapis perannya dianggap tidak penting dalam tim, sehingga merasa profesionalitas mereka diragukan. Terungkap pada pernyataan di bawah ini:

"Iya jadi mereka lebih percaya kalau dietisien itu pekerjaannya itu hanya konseling, malah ada beberapa dokter yang masih berasumsi kalau gizi itu adalah masak...." (P2, perempuan, 30 tahun, S1, dietisien)

Hasil AITCS II pada domain kemitraan pada penelitian ini menunjukan $67,8 \%$ responden melakukan kolaborasi baik, berbeda dengan pernyataan partisipan yang masih terdapat pemahaman berbeda tentang konsep kemitraan. Kemitraan yang diinginkan dalam PKIP adalah model komplementer, yakni tidak ada satu profesi yang lebih dominan dari profesi lain. Namun pada kenyataannya masih ada tenaga kesehatan yang belum memahami peran masingmasing profesi secara benar. Hal ini tampak pada penelitian ini dan juga Utami dimana masih adanya sebagian dokter yang melihat diri mereka sebagai profesi yang dominan dan menjadi penentu kebijakan dalam tim. ${ }^{15,21}$ Pada penelitian ini, partisipan dokter menyatakan bahwa tenaga kesehatan lain dalam tim tugasnya adalah menjalankan instruksi dari dokter. Pernyataan partisipan dokter tersebut didukung partisipan perawat yang menyatakan bahwa mereka bekerja atas dasar instruksi dokter. Penelitian Utami di rumah sakit Panti Rapih dan Fatalina di RSUP Dr. Sardjito, Jogyakarta juga menemukan kondisi yang sama. . $^{5,20}$

Kondisi ini didukung oleh iklim praktik dimana dokter masih dipandang superior dan paling kompeten, sehingga hubungan dokter dengan tenaga kesehatan lain tidak setara dan hierarki. ${ }^{16,21}$ Persepsi dominasi menunjukkan bahwa persepsi ini berakar kuat pada budaya, terutama pada negara yang menganut budaya sosio-hierarki seperti Indonesia. ${ }^{22}$ Perawat juga memiliki konsep penuh kasih dan rendah hati dalam mengabdikan diri untuk kesehatan dan kesejahteraan orang lain, tanpa memikirkan otonomi profesional sejak periode Florence Nightingale. Meskipun sekarang keperawatan telah mengalami transformasi, tingkat pendidikan yang lebih tinggi, emansipasi, praktik mandiri dan peran baru, tetap saja perawat masih memiliki citra diri yang rendah..$^{21,23}$ Selain pada tenaga kesehatan, Wong, dkk menemukan bahwa sebagian mahasiswa bidang kesehatan menyampaikan bahwa dokter memiliki kompetensi yang lengkap dibandingkan profesi kesehatan lainnya sehingga tampak ketidaksetaraan kompetensi yang dimiliki. ${ }^{21}$

Pada domain kemitraan, konsep patient center juga harus dipahami bahwa setiap pasien adalah mitra kerja dalam tim yang bersamasama merencanakan apa yang akan dilakukan tim pada diri pasien. ${ }^{2-4}$ Pengambilan keputusan bersama ditempuh karena tenaga kesehatan bukanlah penentu utama seperti pada konsep hubungan paternalistis. Pengambilan keputusan bersama dengan pasien telah menjadi kebiasaan di dalam praktik sekarang, sebagai bentuk penerapan prinsip etik yakni menghormati otonomi pasien. ${ }^{24}$

\section{b. Komponen kerjasama}

Pengalaman penerapan komponen kerjasama dalam kolaborasi diungkapkan partisipan sebagai bentuk pembagian tugas sesuai kewenangan, melakukan tugas profesi lain dalam bentuk pendelegasian wewenang. 
“..dokter barangkali hanya menetapkan dia DM, nah kami yang bertugas menghitung kebutuhan definitifnya berapa kalori..." (P4, perempuan, 48 tahun, S1, dietisien)

"..karena waktu, banyaknya jumlah pasien sehingga tidak bisa dilakukan oleh dokter sendiri, sehingga melimpahkan lah kewenangan itu kepada perawat...." (P8, laki-laki, 43 tahun, S1, perawat)

Pemahaman pentingnya kerjasama dan adanya motivasi agar melakukan kerjasama juga terungkap dari beberapa partisipan yakni:

“..akreditasi rumah sakit, maka kalau kita anggap main-main kita juga ngga benar. Itu sangat-sangat menurut saya sangat berperan untuk banyak harus berbenah diri ke profesi kita maupun untuk proses kolaborasi dengan nakes yang lain gitu." (P4, perempuan, 48 tahun, S1, dietisien)

Kemitraan mendorong antar profesi untuk menggunakan pengetahuan dan keterampilan masing-masing dalam mengembangkan rencana perawatan, dan seluruh anggota tim terlibat dalam penetapan tujuan bagi masing-masing pasien. ${ }^{2-4,6}$ Sehingga pengambilan keputusan bersama tidak hanya terbatas antara DPJP dengan pasien, tapi dengan semua anggota tim perawatan. Partisipan apoteker mengungkapkan keinginannya agar hal tersebut dapat terlaksana:

“..idealnya sih visit bersama dan menentukan terapi yang terbaik untuk pasien bersama gitu Dok, idealnya seperti itu." (P6, perempuan, 30 tahun, S1, apoteker)

Kerjasama terjadi ketika tenaga kesehatan bekerja sama dan berbagi pengetahuan dan keterampilan. Pada domain kerjasama terkandung penerapan kewenangan dan kompetensi masing-masing profesi, kemudian dielaborasi di dalam tim dan tercipta pembagian tugas yang disepakati bersama. Hasil kuesioner menunjukan sebanyak $82,2 \%$ responden telah melakukan kolaborasi baik pada domain kerjasama, namun partisipan mengungkapkan adanya perbedaan cara pandang terhadap bentuk kerjasama yang selama ini mereka lakukan. Dokter melihat bahwa kerjasama telah terjadi ketika tenaga kesehatan lain membantu pelayanan dengan menjalankan instruksi dari dirinya. ${ }^{16}$ Sedangkan profesi lain, merasakan bahwa mereka masih bekerja sendiri-sendiri atas dasar diagnosis yang sama untuk satu pasien. Bentuk seperti ini dikenal sebagai kolaborasi multiprofesi, yakni bergabungnya dua atau lebih profesi bekerja berdampingan yang tiap profesinya berfokus pada rencana perawatan serta evaluasi sesuai disiplin ilmunya sendiri. ${ }^{2,23}$ Pada kolaborasi interprofesional, beberapa tenaga kesehatan dari latar belakang profesional yang berbeda bekerja sama dengan pasien/keluarga dalam sebuah tim memberikan layanan komprehensif. ${ }^{4}$ Memahami peran dan otoritas setiap profesi kesehatan merupakan faktor penting untuk kerja tim yang efektif. 21,25 Berbagai penelitian menunjukkan bahwa sikap saling menghormati dalam tim interprofesional mungkin terhalang oleh kurangnya pemahaman tentang peran anggota tim, daripada oleh perebutan kekuasaan atau persaingan. ${ }^{18}$ Budaya kerja sama juga dapat dibangun dengan cara menghargai nilai-nilai yang dimiliki satu sama lain yakni etika interprofesional.,26

\section{c. Komponen koordinasi}

Koodinasi dalam pelaksanaan praktik kolaborasi dirasakan penting dalam mempermudah PKIP. Beberapa aspek yang partisipan ungkapkan yakni: kebutuhan akan kesepakatan alur koordinasi, peran profesi penghubung dianggap dapat membantu alur koordinasi dan perlunya pemimpin tim. Kesepakatan antar anggota tim yang dibuat bersama tidak ditemukan pada penelitian ini, seperti pernyataan partisipan ini:

"Kalau kesepakatan tertulis saya belum lihat ya, tapi mungkin kesepakatan tidak tertulis yang sudah tertanam mungkin ya sebagai budaya..." (P1, lakilaki, 48 tahun, dokter spesialis)

Partisipan mengakui pentingnya pemimpin tim dalam PKIP. Kesepakatan tidak tertulis juga tercermin dari pemilihan pemimpin tim, yang secara otomatis memilih dokter sebagai pemimpin tim. Terungkap baik profesi dokter 
ataupun profesi lain menganggap pemimpin tim adalah dokter. Hal ini diungkapkan oleh partisipan dokter dan dietisien:

"..kasus emergency ya dok ya, biasanya itu kalau itu kan kita dokter sebagai leader ya dok ya, nanti perawatnya kan membantu..." (P11, perempuan, 34 tahun, S1, dokter umum)

“..dokter DPJP yang memegang pasien, jadi kita harus berprinsip kita harus memegang ke dia, apapun yang terjadi pada pasiennya yang menjadi dasar dari setiap intervensi yang kita lakukan, asuhan gizi yang kita lakukan, kita harus berpedoman dengan apa yang DPJP tulis." (P2, perempuan, 30 tahun, S1, dietisien)

Partisipan juga menyampaikan bahwa alur koordinasi ini penting dalam menjalankan praktik terkait profesinya, seperti yang disampaikan partisipan berikut:

"..informasi yang jelas, informasi yang tepat dari dokternya sendiri, mengenai penyakit pasiennya. Sebetulnya itu kunci awalnya jadi kalau misalnya dokter menjelaskan diagnosanya apa, karena apa, sekarang mau diapakan, ke kita pun enak memberikan konseling dietnya..." (P2, perempuan, 30 tahun, S1, dietisien)

Pemahaman bahwa alur koordinasi berarti melalui profesi lain sebagai perantara diungkapkan oleh partisipan fisioterapis karena sulitnya berkomunikasi dengan pemimpin tim yakni dokter penanggung jawab pasien (DPJP).

“..kita lapor ke perawat, perawat lapor ke DPJP, baik tidaknya nanti disampaikan oleh perawat..."(P10, perempuan, 42 tahun, S1, fisioterapis)

Koordinasi didefinisikan sebagai seni kerja tim untuk mencapai tujuan organisasi dengan cara kolaboratif di mana terdapat komunikasi dan pertukaran informasi yang efektif di antara para profesional kesehatan. Domain ini membutuhkan kepemimpinan yang baik, pemilihan pemimpin tim dan penetapan tujuan bersama secara jelas., ${ }^{5,10}$ Pada penelitian ini seluruh responden mengatakan bahwa DPJP merupakan pemimpin tim, serupa dengan penelitian Wong, dkk yang menganggap dokter sebagai profesi yang kompeten. ${ }^{21}$ Pemahaman ini tercipta karena sejak dulu dokter merupakan profesi yang mandiri dan dominan daripada profesi kesehatan lain. ${ }^{1,6}$ Dokter dapat bertanggung jawab mulai dari penilaian hingga evaluasi, penyediaan perawatan pasien dan manajemen pengobatan. ${ }^{21}$ Akan tetapi yang dibutuhkan untuk menjadi pemimpin tim nantinya bukan hanya melakukan tata kelola terapeutik tapi juga mampu memberikan panduan yang efektif untuk mengelola tim. Bertanggung jawab untuk mengawasi, mengelola, dan memotivasi anggota tim serta memastikan agar prinsip-prinsip etika interprofesional berjalan. Diharapkan dengan adanya kesepakatan pada nilai dan prinsip moral, pemimpin tim dapat memperbaiki persaingan profesional dan tetap fokus pada kebutuhan pasien.,26 Dokter yang menjadi pemimpin tim, perlu mengasah kemampuannya untuk menilai dinamika yang ada dalam pelayanan kesehatan dan secara konsisten mencari masukan dari tenaga kesehatan lain. ${ }^{2,3,6}$ Pada penelitian ini konsep kepemimpinan yang diterapkan para responden belum sesuai dengan konsep dalam KIP, hal ini dapat terjadi karena belum adanya pemahaman yang sesuai dan tidak adanya kesepakatan bagaimana tim perawatan dibentuk.

Kuesioner AITCS II menunjukan domain koordinasi yang memiliki persentase kolaborasi baik terendah $(66,7 \%)$, hal ini dapat dipengaruhi komponen komunikasi. Dokter yang dianggap sebagai pemimpin tim, belum menerapkan komunikasi interprofesional yang sesuai dan dianggap sebagai hambatan kolaborasi. Pada domain koordinasi, komunikasi antar tenaga kesehatan dalam tim penting agar tercipta kinerja yang baik. Komunikasi interprofesional merupakan kompetensi utama yang wajib dipenuhi para tenaga kesehatan dalam menjalankan PKIP.,26 Komunikasi yang diterapkan adalah komunikasi berbasis kemitraan, yakni komunikasi dua arah..$^{20,22}$ 
Cara komunikasi antar tenaga kesehatan terbagi atas komunikasi langsung serta tidak langsung. Komunikasi langsung merupakan cara yang paling ideal agar tercipta komunikasi dua arah dan terjadi pertukaran informasi secara efektif., ${ }^{2,26}$ Lestari menemukan bahwa kurangnya interaksi langsung serta perbedaan persepsi tentang kebutuhan pasien di antara tenaga kesehatan menjadi salah satu masalah komunikasi yang menghambat praktik KIP. ${ }^{27}$ Kenyataannya komunikasi langsung tidak selalu dapat dilakukan karena keterbatasan waktu, dan jumlah pasien yang melebihi kemampuan sumber daya tenaga kesehatan tertentu. ${ }^{10}$

\section{d. Komponen komunikasi}

Komunikasi yang baik dalam tim menjadi faktor yang dianggap para partisipan sebagai komponen penting dalam berjalannya praktik kolaborasi. Seperti yang diungkapkan partisipan ini:

“..misalkan satu profesi mengadakan komunikasi dengan profesi lain terkait kebutuhan pasien disitulah terjadi kolaborasi..."(P8, laki-laki, 43 tahun, S1, perawat)

Interaksi antar sejawat atau antar profesi dapat berupa komunikasi langsung dengan berdiskusi baik secara bertatap muka ataupun lewat telepon. Partisipan dokter mengungkapkan bahwa interaksi langsung berupa forum diskusi dengan sejawat dilakukan jika dibutuhkan saja:

"..ada kasus yang memang melibatkan beberapa SMF kita ngobrol duduk bareng cari solusi..." (P3, laki-laki, 49 tahun, dokter spesialis)

Komunikasi langsung tersering melalui telepon untuk kebutuhan konfirmasi, seperti partisipan berikut ungkapkan:

“..konfirmasi by phone biasanya...coba konfirmasi dokter misalkan, Dok hari kemarin dapatnya ini ko sekarang ini ya? Oh ternyata ini yang benarnya." (P6, perempuan, 30 tahun, S1, apoteker)
Komunikasi tidak langsung umumnya terjadi lewat rekam medis, resep dan aplikasi media pesan di telepon seluler.

"Nah catatan kami ini berupa saran ke lembar CPPT (Catatan Perkembangan Pasien Terintegrasi) ke dokter. Yang lebih sering dokter itu acc saja dengan memberikan stempel dan paraf di setiap lembar CPPT yang kami tulis bersama dengan perawat dan catatan dokter..." (P4, perempuan, 48 tahun, S1, dietisien)

Cara komunikasi tidak langsung melalui rekam medis diupayakan dapat memfasilitasi pertukaran informasi yang diharapkan. Menurut Lestari, terdapat korelasi kuat dan positif antara pelaksanaan PKIP dengan pengisian Catatan perkembangan pasien terintegrasi (CPPT). Lengkapnya informasi CPPT tergantung pada kepatuhan para tenaga kesehatan dalam mengisinya, dimana lengkapnya informasi secara langsung dapat mendorong pengambilan keputusan bersama. ${ }^{27}$ Claramita membuat konsep panduan komunikasi bertahap yang dimulai penerimaan kolaborasi yang baik, kemudian terbuka atas segala informasi dalam tim dan terakhir nantinya akan tercipta keterbukaan untuk diskusi. Pemimpin tim harus dapat mengupayakan terjadinya pertukaran informasi dua arah, diskusi, dan tindakan saling melengkapi daripada saling menyalahkan sehingga terjadi kesepakatan hingga pengambilan keputusan bersama. ${ }^{28}$ Pada penelitian ini terungkap bahwa komunikasi secara langsung sangat sulit untuk dilakukan karena kesibukan dokter yang dianggap sebagai pemimpin tim. Pada kuesioner AITCS II, komponen komunikasi tidak dianalisis terpisah namun menjadi satu dalam komponen koordinasi dan kemitraan. ${ }^{5}$

\section{Kendala pelaksanaan PKIP di RS}

Selain pemahaman yang berbeda-beda, terungkap beberapa faktor yang dianggap sebagai kendala penerapan PKIP secara ideal, antara lain: ketidaksetaraan, tumpang tindihnya kewenangan, rasio pasien dengan tenaga kesehatan, karakter personal, hambatan komunikasi dan kurangnya dukungan institusi. Ketidaksetaraan tampak dari adanya profesi yang dominan dan profesi lain merasa 
hanya sebagai pendukung saja. Ketidakterbukaan dalam hubungan kolaboratif tampak dari adanya karakter pribadi tenaga kesehatan yang menunjukkan hal tersebut, yakni:

"..kayak sekarang kita misalkan mau ikut visit bareng misalkan, dokter yang ini welcome, dokter yang ini ngga welcome gitu misalnya, jadi kita oh ya udah mundur aja visit sendiri aja gitu." (P6, perempuan, 30 tahun, S1, apoteker)

Budaya sosio-hierarki merupakan hambatan besar dalam pelaksanaan PKIP, terutama pada domain kemitraan. ${ }^{28}$ Konsep kemitraan yang setara harus dimulai sejak masa pendidikan, mengetahui kompetensi diri juga profesi lain serta ditanamkannya prinsip saling menghargai. ${ }^{1,2,4,26}$ Tindakan atau kewenangan yang tumpang tindih antar profesi kesehatan umum terjadi dalam bidang kesehatan, hal ini terkait dengan rasio pasien dan tenaga kesehatan yang tidak seimbang. Ketidaktahuan tenaga kesehatan atas peran profesi lain dalam tim menjadikan sebuah hambatan bekerjasama. Beberapa partisipan membutuhkan pengakuan agar kewenangannya diakui, seperti pada pernyataan berikut:

“..penghambat cuma lebih ke profesi kita itu malah jadi abu-abu kalau misalnya memang kegiatan kita masih dilaksanakan oleh profesi lainnya..." (P2, perempuan, 30 tahun, S1, dietisien)

Beberapa partisipan mengungkapkan bahwa dukungan institusi rumah sakit dalam mendorong terjadinya PKIP sangat penting, baik melalui kebijakan ataupun dukungan fasilitas. Tidak adanya dukungan institusi rumah sakit dalam pembuatan kebijakan terkait KIP, menjadi hambatan terlaksananya PKIP. Hal ini diungkap salah satu partisipan:

"..penghambatnya manajemen yang tidak memfasilitasi kita berkolaborasi..." (P10, perempuan, 42 tahun, S1, fisioterapis)

Dukungan institusi berupa adanya tata kelola yang jelas, protokol terstruktur, batasan kewenangan, dukungan tingkat administratif, dan prosedur operasional bersama (integrated pathway) merupakan pendorong terciptanya PKIP di RS. ${ }^{4,29}$ Dukungan sarana agar akses ke anggota tim lebih dekat, berupa ruangan interaksi tim, teknologi informasi yang tersedia untuk semua anggota tim untuk akses ke rekam medis dikatakan dapat meningkatkan komunikasi interprofesional. ${ }^{29}$

Peraturan atau kebijakan juga berperan penting dalam memfasilitasi PKIP Kolaborasi interprofesional tidak secara khusus tertuang dalam kebijakan-kebijakan nasional, akan tetapi merujuk kepada tujuan pelayanan kesehatan yakni pelayanan yang bermutu yang diamanatkan pada tiap kebijakan terkait pelayanan kesehatan, tentunya dapat diwujudkan dengan PKIP. Kebijakan-kebijakan tingkat nasional tersebut dapat diterapkan dengan melihat apa yang mungkin dapat dilaksanakan di RS oleh manajemen di tingkat lokal. Diharapkan manajemen tidak hanya mengharapkan kolaborasi, tetapi juga memfasilitasi, mengakui, dan menghargai kolaborasi dengan imbalan yang sesuai bagi para tenaga kesehatan yang terlibat. $^{30}$

Komponen pembentuk KIP sangat penting, namun kurangnya informasi tentang KIP menyebabkan pandangan dan pemahaman tentang praktik kolaboratif terbatas, yang kemudian menimbulkan kendala dalam menerapkan KIP yang ideal. ${ }^{15,16,20,21}$ Perbedaan pemahaman dapat diatasi ketika peserta didik profesi kesehatan terbiasa melakukan IPE. Diharapkan kebiasaan berkolaborasi sejak masa pendidikan akan diterapkan dengan baik saat praktik di pelayanan.,22,26 Namun tenaga kesehatan yang dahulunya tidak terpapar IPE, menganggap KIP dilakukan jika terdapat keterbatasan dalam menangani pasien seperti yang tercantum dalam kode etik profesi para tenaga kesehatan. Sehingga penting dilakukannya sosialisasi PKIP serta IPE pada para tenaga kesehatan yang juga sebagai pendidik klinis, karena diharapkan mereka akan menjadi role model.

\section{KESIMPULAN}

Terkait kolaborasi interprofesional, rumah sakit pendidikan menjalankan fungsi pendidikannya 
dengan menjalankan IPE serta fungsi pelayanan dengan menerapkan PKIP. Tenaga kesehatan di RS pendidikan diharapkan dapat menjadi role model KIP bagi para peserta didik tahap profesi. Namun penerapan PKIP yang ideal di RS pendidikan masih menghadapi beberapa kendala. Adanya pemahaman terhadap domain-domain KIP yang belum tepat dalam penelitian ini menimbulkan persepsi bahwa tenaga kesehatan telah menerapkan PIKP dengan baik. Kendala lain yang dihadapi yakni masih adanya stereotip, budaya hierarki, komunikasi satu arah serta kurangnya dukungan institusi.

\section{SARAN}

Rumah sakit diharapkan dapat mendorong terlaksananya PKIP yang lebih baik dengan membuat kebijakan terkait PKIP dan dukungan pelayanan. Institusi pendidikan afiliasi RS dapat bekerja sama melakukan sosialisasi seperti seminar atau pelatihan perihal KIP kepada para tenaga kesehatan khususnya pendidik klinis, sehingga IPE dapat dilaksanakan.

\section{DEKLARASI KEPENTINGAN}

Para penulis mendeklarasikan bahwa tidak terdapat konflik kepentingan apapun terkait studi pada naskah ini.

\section{KONTRIBUSI PENULIS}

Nurul Aida Fathya - Pengembangan usulan penelitian, pengumpulan data, analisis data dan penyusunan rancangan naskah publikasi.

Christantie Effendy - Analisis data, kontribusi pada finalisasi naskah publikasi.

Yayi Suryo Prabandari - Analisis data, kontribusi pada finalisasi naskah publikasi.

\section{DAFTAR PUSTAKA}

1. Higgs J, Croker A, Tasker D, Hummel J, Patton N. Health Practice Relationships. Rotterdam: Sense Publishers; 2014.

2. Thistlethwaite J. Values-based interprofessional collaborative practice : working together in health care. United Kingdom: Cambridge University Press; 2012.
3. IOM (Institute of Medicine). Establishing transdisciplinary professionalism for improving health outcomes: Workshop summary. Washington DC: The National Academies Press; 2013.

4. World Health Organization. Framework for Action on Interprofessional Education and Collaborative; 2010.

5. Orchard C, Pederson LL, Read E, Mahler C, Laschinger $\mathrm{H}$. Assessment of Interprofessional Team Collaboration Scale (AITCS): Further Testing and Instrument Revision. The Journal of Continuing Education in the Health Profession. 2018; 38(1):11-18

6. Borst J. Interprofessional Collaboration: An Introduction. Scientific Professional, Researcher And Educational Publications. Humán Innovációs Szemle. 2011:1.

7. Undang-undang Republik Indonesia nomor 20 tahun 2013 tentang Pendidikan Kedokteran.

8. Peraturan Pemerintah Nomor 93 tahun 2015 Tentang Rumah Sakit Pendidikan.

9. Lembaga akreditasi mandiri pendidikan tinggi kesehatan. Buku 4 pedoman dan matriks penilaian dokumen kinerja dan laporan evaluasi diri akreditasi program studi sarjana kedokteran dan profesi dokter. Jakarta: 2019. 54-55 p.

10. Findyartini A, Kambey DR, Yusra RY, Timor AB, KhairaniaCD, SetyoriniD, etal.Interprofessional collaborative practice in primary healthcare settings in T Indonesia: A mixed-methods study. Journal of Interprofessional Education and Practice. 2019; 17:100279.

11. Peraturan Menteri Kesehatan Republik Indonesia Nomor 30 tahun 2019 Tentang Klasifikasi Dan Perizinan Rumah Sakit.

12. RSUD R Syamsudin SH Kota Sukabumi. 2020.

13. Creswell JW, Creswell JD. Research design: qualitative, quantitative and mixed methods approaches 5th Edition. Los Angeles: SAGE Publications; 2018. 293-294 p.

14. Yusra RY, Findyartini A, Soemantri D. Healthcare professionals perceptions regarding interprofessional collaborative practice in 
Indonesia. Journal Of Interprofessional Education And Practice. 2019; 15:24-29.

15. Utami L, Hapsari S, Widyandana D. Hubungan Antara Sikap Dan Perilaku Kolaborasi Dan Praktik Kolaborasi Interprofesional Di Ruang Rawat Inap Rumah Sakit Panti Rapih. Jurnal Keperawatan Muhammadiyah. 2016; 1(2).

16. SariVR, Hariyati TS, HamidAYS. The association between stereotyping and interprofessional collaborative practice. Enfermeria Clinica. 2018; 28 (Supl 1 Part A):134-138.

17. Martiningsih W. Praktik kolaborasi perawatdokter dan faktor yang memengaruhinya. Jurnal Ners. 2011; 6(2):147-155.

18. Bochatay N, Bajwa M N, Cullati S, Muller-Juge V, Blondon S K, Perron N J, et al. A Multilevel Analysis of Professional Conflicts in Health Care Teams: Insight for Future Training. Academic Medicine. 2017; 92:S84-S92.

19. Peraturan Menteri Kesehatan Republik Indonesia Nomor 519 Tahun 2011 Tentang Pedoman Penyelenggaraan Pelayanan Anestesiologi Dan Terapi Intensif Di Rumah Sakit.

20. Fatalina F, Sunartini, Widyandana D, Sedyowinarso M. Persepsi Dan Penerimaan Interprofessional Collaborative Practice Bidang Maternitas Pada Tenaga Kesehatan. Jurnal Pendidikan Kedokteran Indonesia. 2015; Vol.4 No.1.

21. Wong PS, Hasan SS, Ooi J, Lawrence, Lim SH, Nadarajah VD. Assessment of attitudes for interprofessional team working and knowledge of health professions competencies for final year health professional students. The Asia Pacific Scholar. 2018; Vol. 3 No. 1.

22. Claramita M, Nugraheni MDF, van Dalen J, van der Vleuten C. Doctor-patient communication in Southeast Asia: a different culture?. Advanced Health Science and Education Theory Practice. 2013;18(1):15-31.
23. Roodbol PF. Multiprofessional education to stimulate collaboration: a circular argument and its consequences. GMS Z Med Ausbild. 2010; 27(2):Doc28.

24. Bertens, K. Etika Biomedis. Yogyakarta: Kanisius; 2011. 145-9 p.

25. Lestari E, Stalmeijer RE, Widyandana D, Scherpbier A. Understanding attitude of health care professional teachers toward interprofessional health care collaboration and education in a southeast Asian country. Journal of Multidisciplinary Healthcare. 2018;11:557571.

26. Interprofessional Education Collaborative. Core competencies for interprofessional collaborative practice: 2016 Update. Washington DC: Interprofessional Education Collaborative; 2016.

27. Lestari Y, Saleh A, Pasinringi SA. Hubungan Interprofesional Kolaborasi Dengan Pelaksanaan Catatan Perkembangan Pasien Terintegrasi Di RSUD. Prof. Dr. H.M. Anwar Makkatutu Kabupaten Bantaeng. Jurnal Kesehatan. 2017; $7(1): 85-90$.

28. Claramita M, Riskiyana R, Susilo AP, Huriyati E, Wahyuningsih M, Norcini JJ. interprofessional communication in a sociohierarchical culture: development of the Tri-O guide. Journal of Multidisciplinary Healthcare. 2019; 12:191-204.

29. Manspeaker SA, Hankemeier DA. Challenges to and Resources for Participation in Interprofessional Collaborative Practice: Perceptions of Collegiate Athletic Trainers. J Athl Train. 2019; 54(1):106-114.

30. Leathard A (editor). Interprofessional Collaboration From Policy to Practice in Health and Social Care. New York: Taylor \& Francis e-Library; 2005. 11-52 p. 